\title{
Lateral Ankle Sprains and Their Association with Physical Function in Young Soccer Players
}

This article was published in the following Dove Press journal:

Open Access Journal of Sports Medicine

\author{
Kenichiro Murata' \\ Tsukasa Kumai (iD ${ }^{2}$ \\ Norikazu Hirose ${ }^{2}$ \\ 'Graduate School of Sport Sciences, \\ Waseda University, Nishi-tokyo, Japan; \\ ${ }^{2}$ Faculty of Sport Sciences, Waseda \\ University, Saitama, Japan
}

\begin{abstract}
Purpose: Lateral ankle sprain (LAS) in childhood can result in lateral malleolus avulsion fractures; additionally, bone nonunion may occur. Physical maturity relates to the development of bone morphology and physical functionality. It is unknown how changes in physical functionality attributable to physical maturity affect young soccer players with abnormal lateral malleolus (ALM) morphology. Hence, the present study aimed to investigate the bone morphology of the lateral malleolus in young soccer players and to examine its relationship with physical functionality at different maturity levels.
\end{abstract}

Subjects and Methods: Two hundred and ninety young soccer players aged 6-15 years were included. The presence of ALM was assessed using ultrasonography. The subjects were allocated to three groups based on physical maturity (Pre-, Mid-, and Post-peak height velocity age [PHVA]). The prevalence of ALM and the relationship between ALM and physical maturity were examined for body composition, foot pressure distribution, foot alignment, ankle mobility, and single-leg balance.

Results: The prevalence of ALM was $17.6 \%$. For physical maturity, the post-PHVA group showed a decrease in ankle dorsiflexion and eversion and an increase in one-leg hop distance compared to the Pre-PHVA group ( $\mathrm{P}<0.05)$. In the ALM group, the center of pressure during heel raising was distributed laterally in the Post-PHVA $(\mathrm{P}<0.01)$, and the weightbearing dorsiflexion angle was decreased in the Mid- and Post-PHVA $(\mathrm{P}<0.05)$.

Conclusion: In the Post-PHVA young soccer players, decreased ankle dorsiflexion and eversion and increased one-leg hop distance were observed. The ALM group exhibited lateral loading during heel raising in the Post-PHVA group and decreased weight-bearing ankle dorsiflexion angle in the Mid- and Post-PHVA groups. The findings indicate the importance of secondary prevention of LAS and ultrasonography. Prospective studies of LAS in young athletes are required in the future.

Keywords: lateral ankle sprain, ultrasonography, physical maturity, physical function, soccer

\section{Introduction}

The incidence and recurrence rates of lateral ankle sprains (LAS) have been reported to be higher during sports activities. ${ }^{1}$ As soccer involves repetitive turning, stopping, and jumping motions, it is associated with a high incidence of LAS. ${ }^{2}$ Following LAS injuries, residual pain and ankle dysfunction may result in early progression to osteoarthritis. ${ }^{3,4}$ A previous study reported that $18-47 \%$ of children with a history of LAS develop chronic ankle instability (CAI). ${ }^{5}$ Patients with mechanical instability and lateral malleolus (LM) avulsion have a higher rate of LAS recurrence. ${ }^{6,7}$ An association with functional instability scores for CAI has
Correspondence: Norikazu Hirose Faculty of Sport Sciences, Waseda University, 2-579-15, Mikajima,

Tokorozawa, Saitama 359-II 92, Japan

$\mathrm{Tel} / \mathrm{Fax}+8 \mathrm{I} 42-45 \mathrm{I}-\mathrm{I} 022$

Email toitsu_hirose@waseda.jp
Open Access Journal of Sports Medicine 2021:I2 I-10

(c) (i) @ $\odot 2021$ Murata et al. This work is published and licensed by Dove Medical Press Limited. The full terms of this license are available at https://www.dovepress.com/terms. (c) ${ }_{\mathrm{BY}} \mathrm{NC}$ php and incorporate the Creative Commons Attribution - Non Commercial (unported, v3.0) License (http://creativecommons.org/licenses/by-nc/3.0/). By accessing the work you hereby accept the Terms. Non-commercial uses of the work are permitted without any further permission from Dove Medical Press Limited, provided the work is properly attributed. For permission for commercial use of this work, please see paragraphs 4.2 and 5 of our Terms (https://www.dovepress.com/terms.php). 
also been reported. ${ }^{8}$ Structural changes at the ligament and bone level due to childhood LAS may be associated with progression to CAI secondary to LAS.

Both ligamentous injuries and LM avulsion fractures can occur in childhood. The use of ultrasonography for diagnosing LAS in childhood can reveal the presence or absence of ligamentous injuries and avulsion fractures and can quantify the degree of laxity in real-time. Previous reports indicated that $34-80 \%$ and $35-62 \%$ of both pediatric and adolescent patients presenting to the hospital with ankle sprains had ligamentous injuries and LM avulsion fractures, respectively. ${ }^{7,9}$ Additionally, LM avulsion fractures often occur around 8 years of age in first time LAS, and the rate of ligament damage increases by $12-14$ years of age. ${ }^{7,10}$ Only $17-35 \%$ of avulsion fractures healed, ${ }^{7,11}$ with the recurrence rate being higher in the avulsion fracture group. ${ }^{7}$ Moreover, another previous study showed that pediatric patients with $\mathrm{CAI}$ underwent surgery due to bone fragments after an LM avulsion fracture. ${ }^{12}$ These reports suggest that they may be associated with mechanical instability due to avulsion fractures, functional instability due to mechanoreceptor impairment, and recurrence of LAS as shown in the CAI model. ${ }^{13}$ To account for LM avulsion fractures, studies investigating LAS in both pediatric and adolescent patients must include imaging findings.

Risk factors for LAS in adults have been reported to be high body mass index (BMI) and a history of ankle sprains, ${ }^{14,15}$ reduced ankle dorsiflexion, ${ }^{16,17}$ and decreased Star Excursion Balance Test scores and single-leg hop distance $^{18-20}$ on the basis of systematic reviews and metaanalyses. A lateral shift in foot pressure distribution has also been identified as a risk factor for the onset of LAS based on kinetic and kinematics data. ${ }^{21}$ To our knowledge, prospective research has yet to be conducted to evaluate whether these risk factors also make the pediatric and adolescent athlete more prone to LAS.

The level of physical maturity needs to be considered when focusing on both pediatric and adolescent subjects. Previous studies reported that physical functionality such as muscle strength and balance differed depending on the level of physical maturity. ${ }^{22,23}$ The peak height velocity age (PHVA) is an indicator of physical maturity, ${ }^{24}$ and the use of the PHVA to examine physical function according to physical maturity in both pediatric and adolescent subjects may aid in clarifying the differences in physical functionality between child and adult athletes. Taking into account the differences in physical function based on maturity, it is necessary to investigate whether the impaired physical function caused by the presence of LM avulsion fractures leads to the same impaired function in childhood as in adults, in terms of diagnosis and treatment after LAS in childhood.

LAS in both pediatric and adolescent athletes requires appropriate diagnosis and treatment based on physical maturity because of the risk of complications such as cartilage fractures and the prevalence of permanent sequelae. ${ }^{7,9-12}$ To achieve this, it is necessary to understand the physical characteristics of athletes with LAS, taking into account individual differences in the level of maturity among young athletes. Hence, the present study aimed to investigate the prevalence of LM morphological abnormalities among pediatric and adolescent soccer players and examine physical function characteristics based on physical maturity. The present study was designed to reveal foot pressure distribution, foot/ankle alignment and flexibility, and single-leg balance ability among soccer players aged 6-15 years with LM morphological abnormalities. We hypothesized the following: (1) the physical characteristics of players before and after PHVA would differ, (2) after PHVA players would have physical characteristics similar to those observed in adulthood, (3) players with LM morphological abnormalities would have impaired physical function even before PHVA. The findings from this study will potentially aid in secondary prevention of the development of functional/structural deficiencies and CAI after LAS by investigating the history of LAS in both pediatric and adolescent players and by determining the characteristics of their physical functionalities.

\section{Subjects and Methods}

This study had a cross-sectional research design. The subjects were recruited from youth soccer club teams located in the area around Waseda University in Tokyo. The subjects who (1) agreed on the purpose of the study and measurement risks; (2) were 6-15 years of age; (3) obtained consent from their parents; and (4) were able to participate in all measurements were included in this study. However, players who were not able to play soccer because of trauma or disability at the time of investigation and who exhibited difficulty in completing the measurements, for example, they could not understand the methodology used for the measurements, were excluded. This study was conducted in accordance with the principles outlined in the Declaration of Helsinki and the Ethical Guidelines for Medical and Health Research 


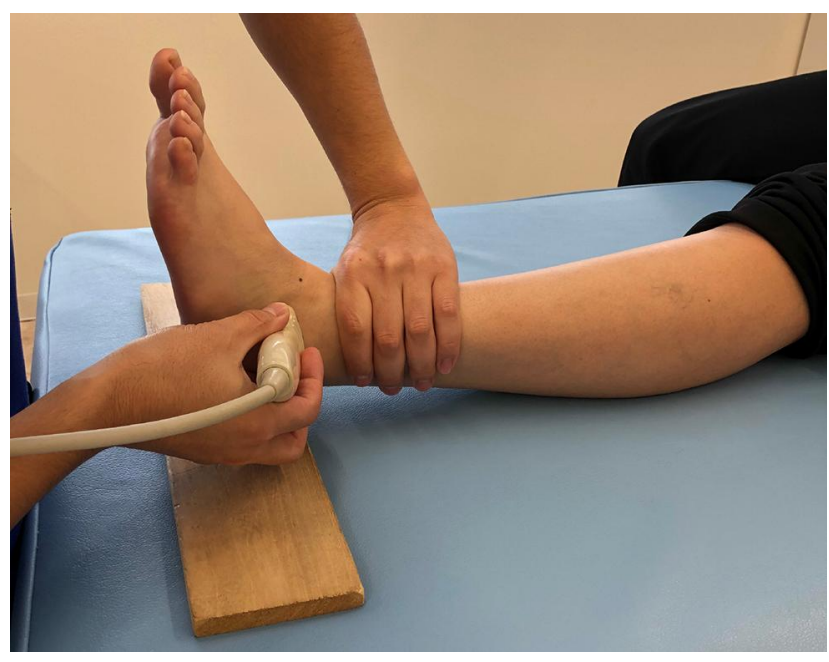

Figure I Measurement of the bone morphology of the anterior talofibular ligament attachment. The examiner applied a manual anterior drawer stress.

Involving Human Subjects and was approved by the ethics committee of Waseda University (\#2018-086). All subjects and their parents provided informed consent in writing.

The subjects responded to a questionnaire about their past history of injuries and soccer activities before the measurements were conducted. All examiners obtained the measurements with the results of the questionnaire blinded. The PHVA was calculated using the AUXAL software version 2.0.1 (Scientific Software International Inc., Skokie, IL, USA). The subjects were classified into three groups based on the PHVA: -1.0 year $>$ PHVA (Pre-PHVA), -1.0 year $\leq$ PHVA $\leq+1.0$ year (Mid-PHVA), and +1.0 year $<$ PHVA (Post-PHVA). The outcome parameters of interest in this study were the bone morphology of the anterior talofibular ligament (ATFL) attachment to the LM, age, height, weight, BMI, foot pressure distribution, foot alignment, ankle range of motion (ROM), and single-leg balance.

The bone morphology of the ATFL attachment to the LM was observed. The subjects placed their heels on the examination table with their ankles in the slightly plantar flexion position. The examiner applied extension stress to the ATFL using a manual anterior drawer stress procedure (Figure 1). From the bone morphology of LM, we classified the subjects into the abnormal LM (ALM) and the normal (N) groups. Based on the findings from a previous study, we defined ALM as the state in which the ATFL attachment is separated from the LM during a manual anterior drawer stress procedure, and Normal LM as the state in which bone continuity is maintained (Figure 2). ${ }^{25}$ One examiner performed ultrasonography using an ultrasound system (LOGIQ e; GE Healthcare, Tokyo, Japan) and a linear ultrasound transducer probe (12L-RS, 5-13 MHz; GE Healthcare, Tokyo, Japan), and the results were blinded to the other examiners. The sensitivity and specificity of the test were reported to be $81-100 \%$ and $85-100 \%$, respectively. ${ }^{10,26}$

Plantar pressure distribution was measured for $10 \mathrm{~s}$ in the static standing and heel-raising positions. After resynthesizing the data, the center of pressure (COP) for the left and right feet was shown in the coordinates of the posterior-anterior (P-A) and medial-lateral (M-L) components (Figure 3). We used a plate-type Twin Gravicorder GP-6000 and an MD-1000 device (Anima Co., Ltd., Tokyo, Japan). ${ }^{27}$ A previous study reported intraclass coefficients (ICCs) of 0.73 and 0.84 for P-A and M-L while standing and 0.69 and 0.82 for P-A and M-L during the heel raise, respectively. ${ }^{27}$

As for foot alignment, the leg-heel angle, defined as the angle between the lower leg axis and the calcaneal axis, was measured in weight-bearing and non-weight-bearing positions (Figure 4A and B). In the weight-bearing position, subjects were in the static standing position with the center of the calcaneus and the second metatarsal axis aligned with two parallel lines set up on a platform. The examiner marked the center of the proximal and distal calcaneus and recorded the images at a fixation point placed one meter behind the

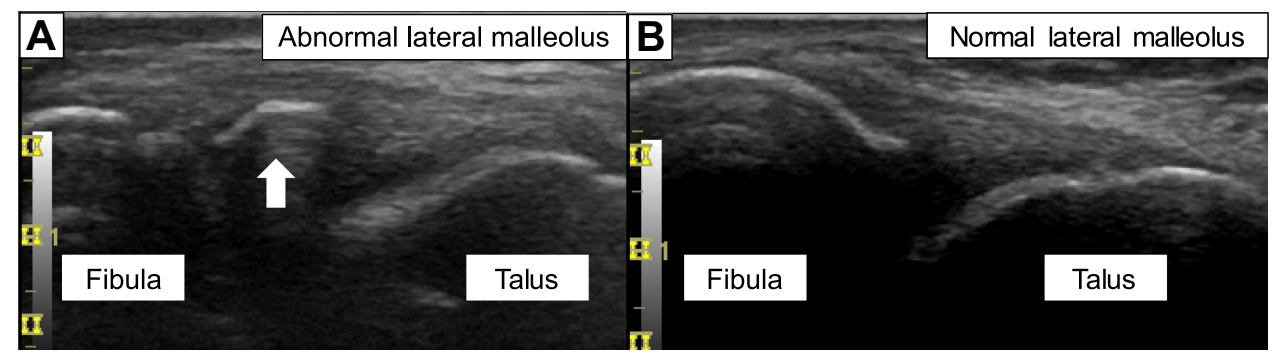

Figure 2 Lateral malleolus morphology and anterior talofibular ligament; (A) An abnormal lateral malleolus, white arrow: the separation of the anterior talofibular ligament attachment from the base bed, (B) A normal lateral malleolus and anterior talofibular ligament. 


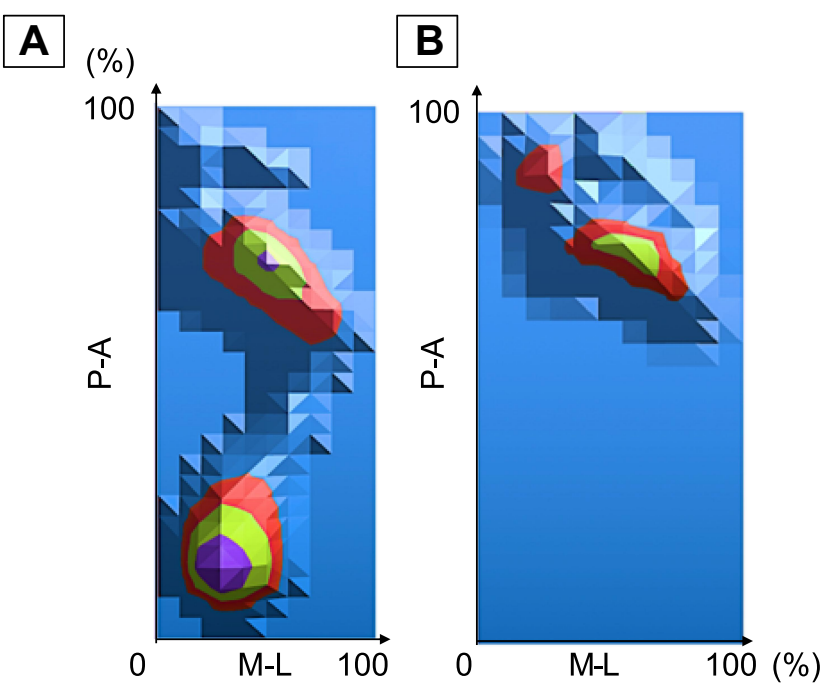

Figure 3 Distribution of plantar pressure and the center of pressure. Plantar pressure distribution for the right foot in the (A) standing position and (B) heel raising position.

Abbreviations: P-A, posterior-anterior; M-L, medial-lateral.

subjects. In the non-weight-bearing position, the subjects were in the prone position on the examination table with the distal lower leg extended from the table. The examiner placed the subjects in the neutral position of internal and external rotation of the lower legs and then recorded the images from a distance of $1 \mathrm{~m}$ above the subjects. The legheel angle was analyzed from the image data using ImageJ (US National Institutes of Health, Bethesda, MD, USA). The direction of inversion $(+)$ and eversion $(-)$ was defined in relation to the lower leg axis. The inter-rater ICCs were reported to be 0.90 and 0.97 in the weight-bearing and nonweight-bearing positions, respectively. ${ }^{27}$

The forefoot angle was measured as the angle between the line connecting the plantar surfaces of the thenar and hypothenar eminences and the line perpendicular to the calcaneal axis in the non-weight-bearing position (Figure 4C). Image data were used for the non-weight-bearing position of the leg-heel angle measurements and were analyzed using ImageJ (US National Institutes of Health, Bethesda, MD, USA). The direction of inversion $(+)$ and eversion $(-)$ was defined in relation to the line perpendicular to the calcaneal axis. The inter-rater ICC was reported to be $0.93 .^{27}$

With respect to the ankle ROM, the dorsiflexion and plantar flexion angles were measured in the knee extension position. The ROM was measured as the angle between the fibular axis and the fifth metatarsal axis. The weight-bearing dorsiflexion ROM was measured in the lunge position with the measured side forward. With the knee joint and toes

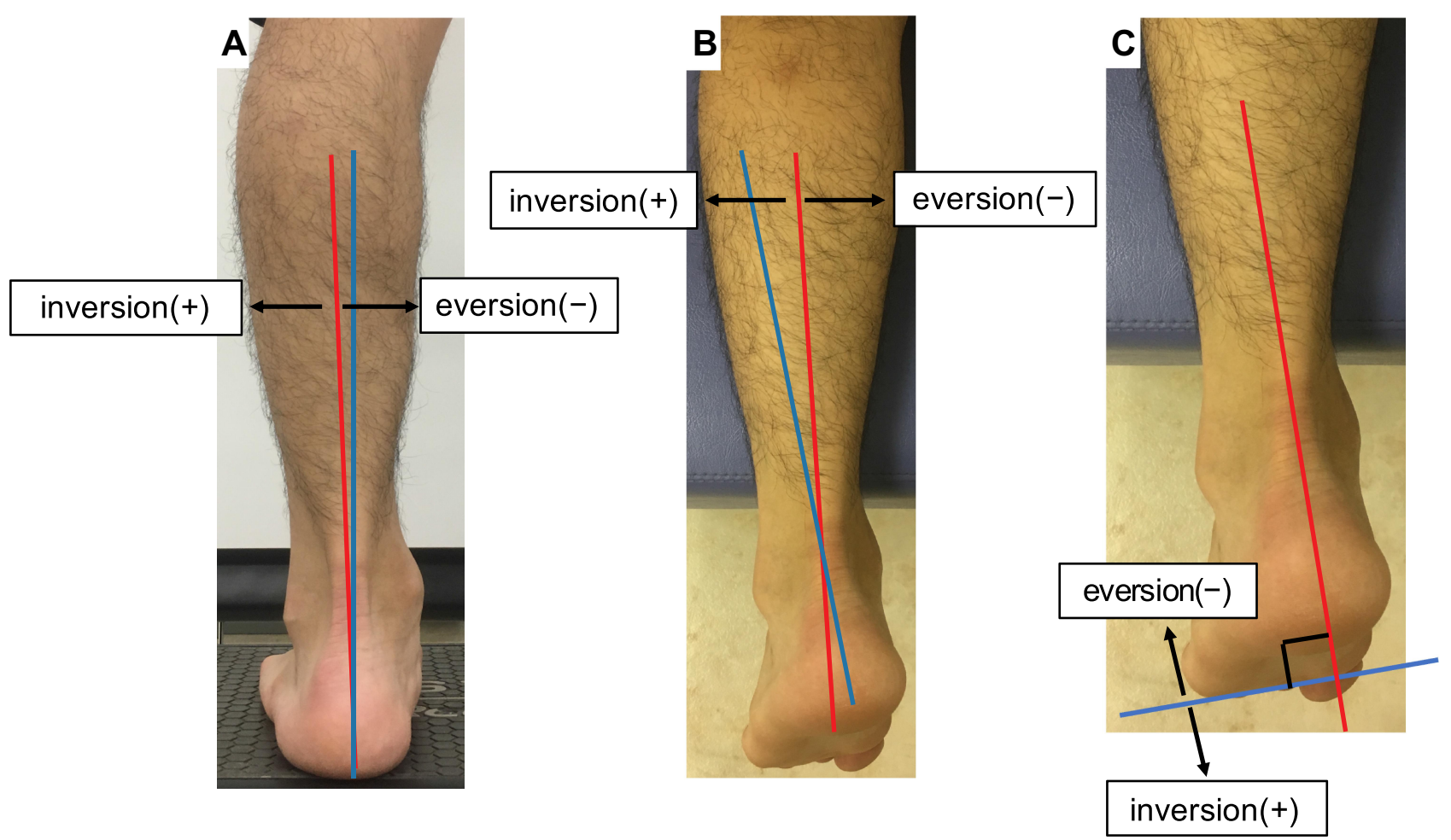

Figure 4 Foot alignment. (A) leg-heel angle (weight-bearing position), (B) leg-heel angle (non-weight-bearing position), (C) forefoot angle to the hindfoot axis. Red line, axis of reference; Blue line, axis of movement. 


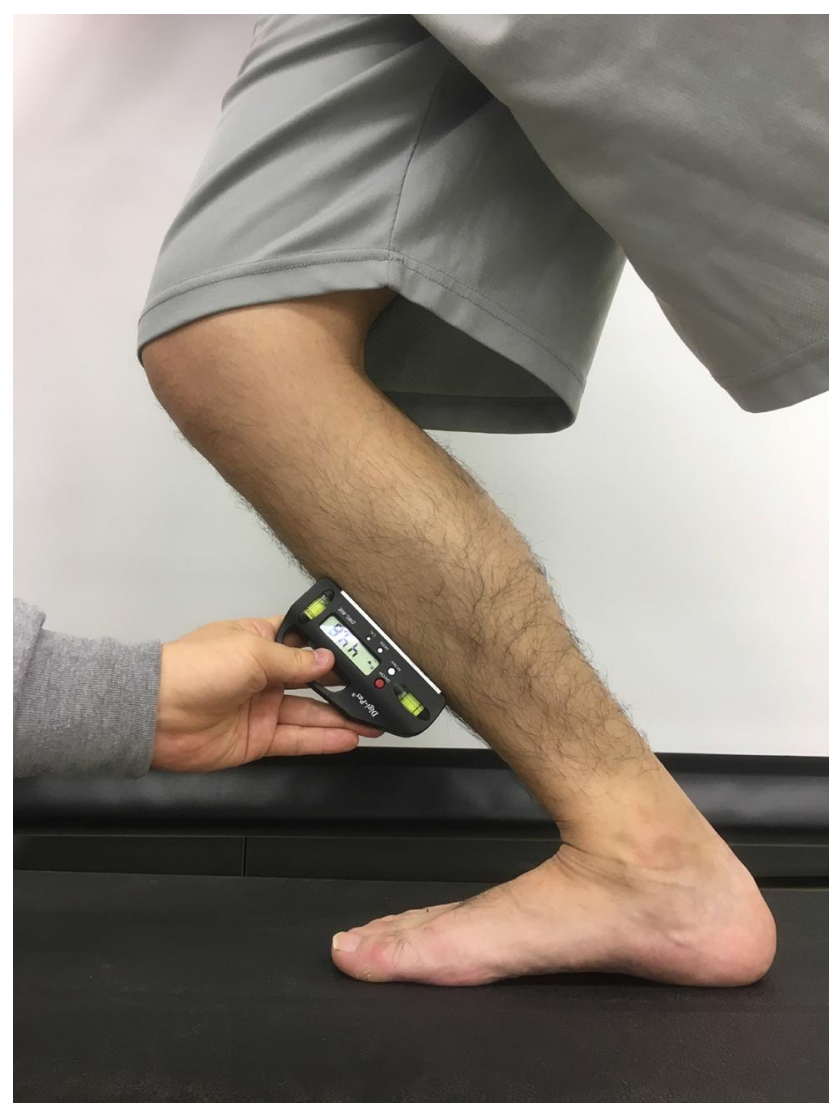

Figure 5 Weight-bearing dorsiflexion angle. The lower leg was tilted forward, and maximum dorsiflexion was performed with the sole placed flat on the floor.

aligned, the lower leg was tilted forward, and maximum dorsiflexion was performed with the sole placed flat on the floor (Figure 5). For the weight-bearing dorsiflexion ROM measurement, a digital inclinometer (DWL-80E; JSB Tech Japan Co., Ltd. and Digi-Pas Japan, Tokyo, Japan) was placed at the center of the tibia and the angle between the tibia and vertical axis from the floor was determined. The intra-rater ICC $(1,1)$ and inter-rater $\operatorname{ICC}(2,2)$ were reported to be 0.99 and 0.98 , respectively. ${ }^{17}$
Regarding single-leg balance ability, the Y-balance test was employed to measure the distance reached by the lower limb in three directions (anterior, posterolateral, and posteromedial) from the single-leg standing position with the subject's hand placed on the hip (Figure 6A). The values obtained were analyzed as standardized values with the spine--malleolar distance. The intra-rater $\operatorname{ICC}(1,2)$ and inter-rater ICC $(2,1)$ were reported to be $0.85-0.96$ and $0.67-0.93$, respectively. ${ }^{28}$ In the one-leg hop test, the subjects were instructed to hop anteriorly and laterally from a single-leg standing position, and the distance reached by their foot after landing was measured, respectively (Figure $6 \mathrm{~B}$ and $\mathrm{C})$. The distance was analyzed as standardized values with height. The intra-rater ICC $(1,2)$ was reported to be $0.97 .^{29}$

\section{Statistical Analysis}

As the main outcome measure, the prevalence of ALM in young soccer players was calculated from ultrasonography results. A two-way analysis of variance was performed to compare the continuous variables of foot COP values, foot alignment, ankle ROM, and single-foot balance between the three groups (Pre-, Mid-, and Post-PHVA) and also to compare the ALM and $\mathrm{N}$ groups within each PHVA groups. The Tukey method was used as a post hoc test. Statistical analyses were performed using IBM SPSS Statistics version 25 (IBM Corp., Armonk, NY, USA).

\section{Results}

In total, 290 young soccer players (mean \pm standard deviation [SD]: age, $11.9 \pm 2.0$ years; height, $147.6 \pm 14.0 \mathrm{~cm}$; weight, $38.7 \pm 10.3 \mathrm{~kg}$; BMI, $17.4 \pm 2.2 \mathrm{~kg} / \mathrm{m}^{2}$ ) were included as subjects in this study. Of these subjects, 239 and 51 were allocated to the $\mathrm{N}$ and ALM groups,
A

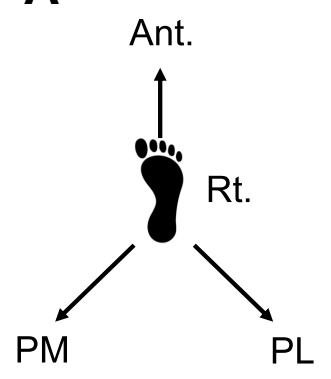

B

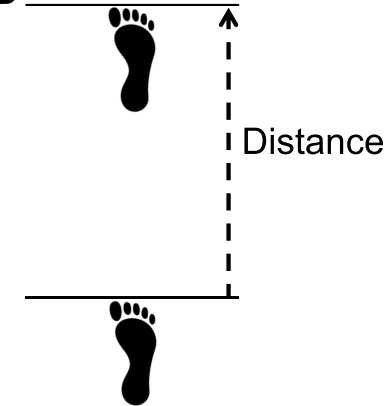

C

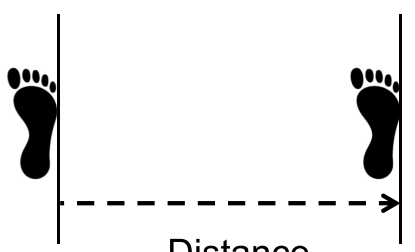

Distance

Figure 6 Dynamic single-leg stability. (A) Y-balance test. (B) One-leg hop test (forward). (C) One-leg hop test (lateral). Abbreviations: Rt., right foot; Ant., anterior; PM, posteromedial; PL, posterolateral. 
Table I Characteristics of the N and ALM Groups

\begin{tabular}{|l|l|l|l|}
\hline Variables & $\begin{array}{l}\text { N Group } \\
(\mathbf{n}=\mathbf{2 3 9})\end{array}$ & $\begin{array}{l}\text { ALM Group } \\
(\mathbf{n}=\mathbf{5} \text { I) }\end{array}$ & P value \\
\hline Age (years) & $11.9 \pm 2.0$ & $12.0 \pm 2.0$ & 0.55 \\
Height $(\mathrm{cm})$ & $147.4 \pm 13.8$ & $148.6 \pm 13.1$ & 0.57 \\
Weight $(\mathrm{kg})$ & $38.6 \pm 10.4$ & $39.2 \pm 10.1$ & 0.73 \\
BMI $\left(\mathrm{kg} / \mathrm{m}^{2}\right)$ & $17.4 \pm 2.2$ & $17.5 \pm 2.4$ & 0.88 \\
Competition history & $68.7 \pm 27.1$ & $69.4 \pm 30.0$ & 0.87 \\
(months) & & & \\
\hline
\end{tabular}

Notes: All results are shown as means \pm standard deviation. None of the variables significantly differed.

Abbreviations: N, normal; ALM, abnormal lateral malleolus; BMI, body mass index.

respectively (Table 1). The overall prevalence of ALM was $17.6 \%$.

The values for variables measured in the $\mathrm{N}$ and ALM groups during the PHVA phase are summarized in Table 2, and significant differences between the three groups are presented in Figure 7. The COP for M-L during the heel raise indicated significantly higher lateral loading in the ALM group for subjects with post-PHVA (N group: $48.4 \pm$ 4.5\%; ALM group: $55.1 \pm 3.8 \% ; \mathrm{F}=11.395, \mathrm{P}=0.002$ ). Moreover, the weight-bearing ankle dorsiflexion angle was significantly decreased in the ALM group for subjects with mid-PHVA (N group: $42.9 \pm 6.8^{\circ}$; ALM group: $37.4 \pm$ $7.7^{\circ} ; \mathrm{F}=9.799, \mathrm{P}=0.002$ ) and post-PHVA ( $\mathrm{N}$ group: 43.0 $\pm 7.0^{\circ}$; ALM group: $36.0 \pm 5.5^{\circ} ; \mathrm{F}=5.300, \mathrm{P}=0.027$ ).

\section{Discussion}

The primary purpose of this study was to determine the prevalence of ALM among young soccer players. The secondary aim was to investigate the characteristics of players with ALM in terms of body composition, foot morphology, joint mobility, balance ability, and maturity stage. Our study findings consequently indicated that $17.6 \%$ of subjects had ALM. In the PHVA phase, ankle dorsiflexion was decreased post-PHVA compared to prePHVA. Additionally, leg-heel angle on weight-bearing showed a gradual decrease in the eversion angle from that pre-PHVA. Moreover, one-leg hop distance was increased mid-, and post-PHVA compared with that prePHVA. The subjects with ALM exhibited lateral loading during the heel raise in the post-PHVA group and a decreased weight-bearing ankle dorsiflexion angle in the mid- and post-PHVA groups.

The prevalence of ALM in young soccer players $(17.6 \%)$ reported in this study, was lower than that determined by previous studies $(26-30 \%$ in both adolescent patients with LAS). ${ }^{9,11}$ The differences in the severity

Table 2 Clinical and Demographic Characteristics for the $\mathrm{N}$ and ALM Groups Based on the PHVA Phase

\begin{tabular}{|c|c|c|c|c|c|c|c|c|c|}
\hline \multirow[t]{2}{*}{ Variables } & \multicolumn{3}{|l|}{ Pre-PHVA } & \multicolumn{3}{|l|}{ Mid-PHVA } & \multicolumn{3}{|l|}{ Post-PHVA } \\
\hline & $\begin{array}{l}N \text { group } \\
(n=|3|)\end{array}$ & $\begin{array}{l}\text { ALM group } \\
(n=28)\end{array}$ & $P$ value & $\begin{array}{l}N \text { group } \\
(n=77)\end{array}$ & $\begin{array}{l}\text { ALM group } \\
(n=17)\end{array}$ & $P$ value & $\begin{array}{l}N \text { group } \\
(n=31)\end{array}$ & $\begin{array}{l}\text { ALM group } \\
(n=6)\end{array}$ & $P$ value \\
\hline BMI $\left(\mathrm{kg} / \mathrm{m}^{2}\right)^{\mathrm{abc}}$ & $16.6 \pm 1.9$ & $16.6 \pm 2.3$ & 0.96 & $18.1 \pm 1.9$ & $18.5 \pm 2.4$ & 0.44 & $19.4 \pm 1.9$ & $18.8 \pm 0.6$ & 0.50 \\
\hline Standing COP M-L (\%) & $46.5 \pm 3.5$ & $47.0 \pm 3.4$ & 0.52 & $46.4 \pm 3.1$ & $47.2 \pm 3.1$ & 0.28 & $46.3 \pm 3.1$ & $47.3 \pm 3.2$ & 0.48 \\
\hline Standing COP A-P (\%) & $46.3 \pm 5.2$ & $44.4 \pm 5.1$ & 0.07 & $46.8 \pm 5.6$ & $47.8 \pm 4.6$ & 0.47 & $47.6 \pm 5.9$ & $46.8 \pm 5.8$ & 0.77 \\
\hline Heel-raising COP M-L (\%) & $49.4 \pm 4.3$ & $50.0 \pm 4.2$ & 0.49 & $48.9 \pm 4.2$ & $49.6 \pm 5.4$ & 0.54 & $48.4 \pm 4.5$ & $55.1 \pm 3.8$ & $<0.01^{e}$ \\
\hline Heel-raising COP A-P (\%) & $71.4 \pm 3.8$ & $70.9 \pm 3.2$ & 0.46 & $71.6 \pm 2.8$ & $72.3 \pm 3.9$ & 0.37 & $72.9 \pm 3.0$ & $70.6 \pm 2.6$ & 0.09 \\
\hline Ankle dorsiflexion $\left({ }^{\circ}\right)^{c}$ & $16.9 \pm 5.3$ & $16.4 \pm 6.0$ & 0.67 & $15.4 \pm 6.0$ & $\mid 4.1 \pm 5.3$ & 0.38 & $13.8 \pm 6.5$ & $13.3 \pm 4.7$ & 0.88 \\
\hline Ankle plantar flexion $\left({ }^{\circ}\right)^{a}$ & $55.0 \pm 6.6$ & $56.5 \pm 7.2$ & 0.25 & $49.8 \pm 7.0$ & $53.4 \pm 8.4$ & 0.05 & $52.4 \pm 5.0$ & $53.5 \pm 4.0$ & 0.60 \\
\hline WB ankle dorsiflexion $\left({ }^{\circ}\right)^{\text {ad }}$ & $44.9 \pm 7.0$ & $46.0 \pm 7.3$ & 0.45 & $42.9 \pm 6.8$ & $37.4 \pm 7.7$ & $<0.01^{e}$ & $43.0 \pm 7.0$ & $36.0 \pm 5.5$ & $0.03^{f}$ \\
\hline LHA WB $\left({ }^{\circ}\right)^{\text {ad }}$ & $-7.4 \pm 5.6$ & $-6.8 \pm 5.1$ & 0.58 & $-3.9 \pm 6.6$ & $-6.0 \pm 4.3$ & 0.17 & $-5.1 \pm 4.5$ & $-3.3 \pm 6.1$ & 0.39 \\
\hline LHA NWB $\left(^{\circ}\right)$ & $5.4 \pm 8.4$ & $7.3 \pm 6.9$ & 0.23 & $5.5 \pm 9.8$ & $7.8 \pm 9.1$ & 0.34 & $6.0 \pm 7.1$ & $5.8 \pm 13.8$ & 0.96 \\
\hline Forefoot angle $\left({ }^{\circ}\right)$ & $7.1 \pm 10.2$ & $6.6 \pm 8.6$ & 0.80 & $6.7 \pm 9.1$ & $9.0 \pm 6.6$ & 0.30 & $6.7 \pm 9.4$ & $\mathrm{II} . \mathrm{I} \pm 5.8$ & 0.28 \\
\hline Y-balance ant. (\%) & $76.0 \pm 11.2$ & $77.5 \pm 10.7$ & 0.49 & $75.0 \pm 7.1$ & $71.9 \pm 6.4$ & 0.07 & $74.6 \pm 7.8$ & $74.2 \pm 5.0$ & 0.91 \\
\hline Y-balance med. (\%) & $112.4 \pm 17.4$ & $112.8 \pm 10.4$ & 0.90 & $113.5 \pm 11.7$ & $113.8 \pm 9.2$ & 0.91 & $115.4 \pm 11.7$ & $109.9 \pm 13.2$ & 0.32 \\
\hline Y-balance lat. (\%) & $109.6 \pm 16.7$ & $110.5 \pm 15.6$ & 0.80 & $113.0 \pm 11.4$ & $108.7 \pm 9.8$ & 0.12 & $112.0 \pm 13.3$ & $108.6 \pm 11.4$ & 0.57 \\
\hline OLHT ant. (\%) ${ }^{\mathrm{ac}}$ & $94.9 \pm 14.9$ & $95.8 \pm 13.9$ & 0.74 & $103.3 \pm 15.0$ & $104.6 \pm 10.3$ & 0.71 & $103.8 \pm 12.3$ & $103.0 \pm 18.5$ & 0.89 \\
\hline OLHT lat. (\%) ${ }^{\text {ad }}$ & $73.5 \pm 11.9$ & $74.3 \pm 11.2$ & 0.73 & $78.1 \pm 10.8$ & $78.5 \pm 10.2$ & 0.86 & $79.5 \pm 10.0$ & $77.6 \pm 11.5$ & 0.66 \\
\hline
\end{tabular}

Notes: All results are shown as means \pm standard deviation. ${ }^{\mathrm{a}} \mathrm{P}<0.0 \mathrm{I}$ between Pre-PHVA and Mid-PHVA group; ${ }^{\mathrm{b}} \mathrm{P}<0.0 \mathrm{O}$ between Mid-PHVA and Post-PHVA group; ${ }^{\mathrm{C}} \mathrm{P}<$ 0.01 between Pre-PHVA and Post-PHVA group; ${ }^{\mathrm{d} P}<0.05$ between Pre-PHVA and Post-PHVA group; ${ }^{\mathrm{P}}<0.0 \mathrm{I}$ between $\mathrm{N}$ and ALM group; ${ }^{\mathrm{f}}<<0.05$ between $\mathrm{N}$ and ALM group.

Abbreviations: N, normal; ALM, abnormal lateral malleolus; PHVA, peak height velocity age; Pre-PHVA, $-I .0$ year > PHVA; Mid-PHVA, - I.0 year $\leq$ PHVA $\leq+I .0$ year; Post-PHVA, + I.0 year < PHVA; BMI, body mass index; COP, center of pressure; M-L, medial-lateral; A-P, anterior-posterior; WB, weight-bearing; LHA, leg-heel angle; NWB, non-weight-bearing; ant., anterior; med., medial; lat., lateral; OLHT, one-leg hop test. 

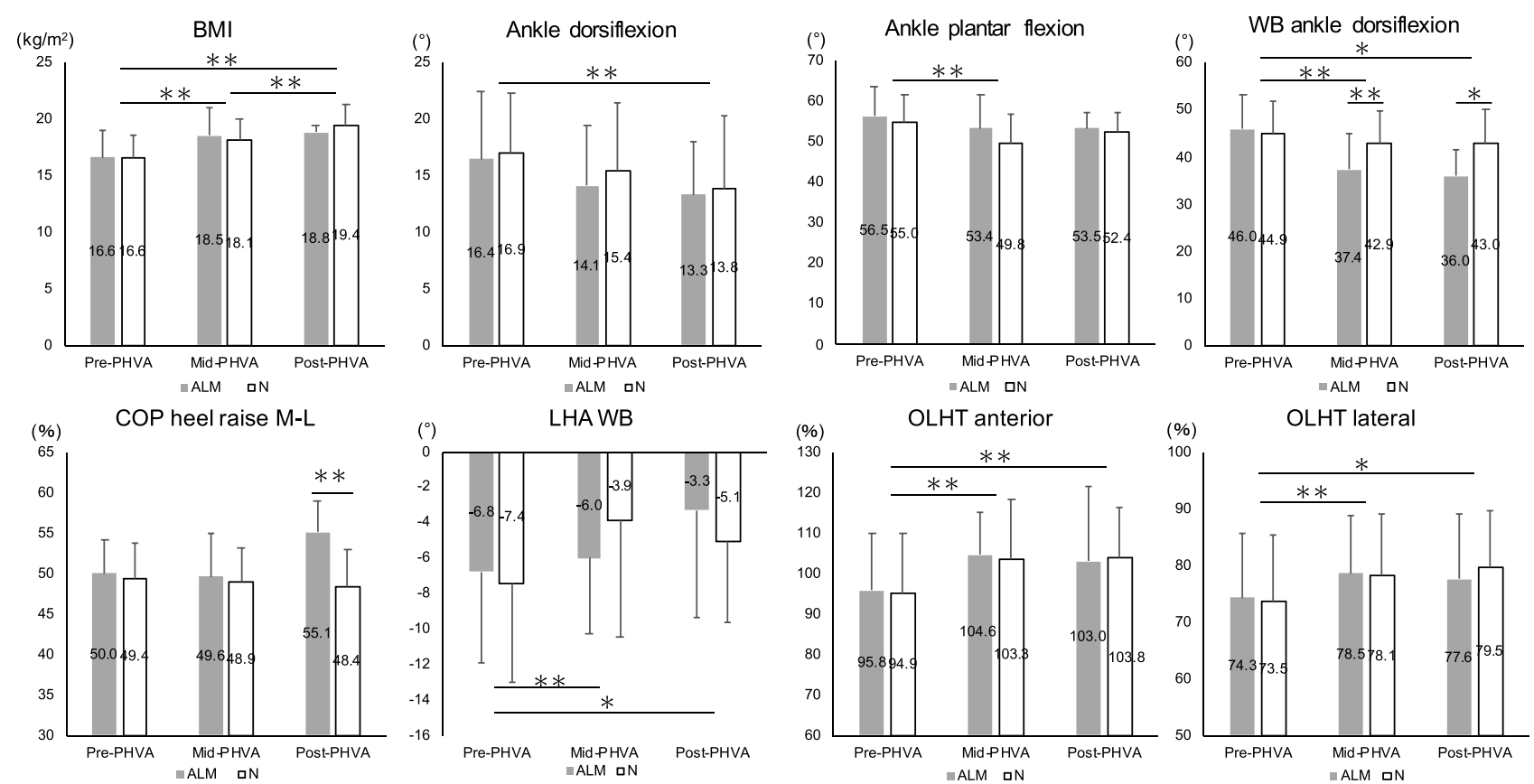

Figure 7 Comparison of the ALM and N groups during the PHVA phase. $* \mathrm{P}<0.05 ; * * \mathrm{P}<0.01$.

Abbreviations: ALM, abnormal lateral malleolus; N, normal; PHVA, peak height velocity age; Pre-PHVA, -1.0 year > PHVA; Mid-PHVA, -1.0 year $\leq$ PHVA $\leq+1.0$ year; Post-PHVA, +I.0 year < PHVA; BMI, body mass index; WB, weight-bearing; COP, center of pressure; M-L, medial-lateral; LHA, leg-heel angle; OLHT, one-leg hop test.

among the subjects included in each study might be the reason for this discrepancy. The present study included young soccer players who were considered healthy, whereas the previous studies only included patients who required medical attention. Furthermore, we should remember that $64 \%$ of patients with ALM in a previous study could not fully recover from fractures, ${ }^{11}$ and the presence of LM avulsion fractures is a possible risk factor for conservative treatment failure in adult patients with acute ankle sprains. ${ }^{30}$ Thus, identifying whether players have ALM by using noninvasive procedures such as ultrasonography is vital to mitigate recurrent ankle sprains.

Concerning the effect of physical maturity, the decreased ankle dorsiflexion and eversion and the increased one-leg hop distance were observed in the postPHVA when compared with the pre-PHVA group. In a previous study of college athletes, weight-bearing ankle dorsiflexion and leg-heel angle were reported to be approximately $42^{\circ}$ and $3^{\circ}$, respectively, as was similar to the mid- and post-PHVA group in this study. ${ }^{17,27}$ Moreover, in the one-leg hop test, it was reported that the jumping ability was greater in the mid-PHVA phase. ${ }^{22}$ Our results regarding mid- and post-PHVA were similar to those from a previous study which included university students. ${ }^{29}$ These results suggest that the foot morphology for weight-bearing, ankle joint mobility, and one-leg hopping function among the pre-PHVA phase players differed from those among the mid- and postPHVA phase players. Of note, the post-PHVA players had measurements similar to those of adult players.

The ALM group with post-PHVA exhibited more lateral loading during the heel raise than the $\mathrm{N}$ group. Additionally, the ALM group with mid- and post-PHVA showed a decrease in the weight-bearing ankle dorsiflexion angle compared to the $\mathrm{N}$ group. These findings suggest the composite influence of changes in foot morphology with physical maturity and the characteristics of LAS observed only in the ALM group. In this study, we could not pinpoint the exact reason for these findings. We speculate that lateral loading during the heel raise in the ALM group with post-PHVA might have been influenced by the changes in foot morphology throughout growth. The foot arch rapidly develops from 7 to 10 years of age and matures at approximately 13 years of age. ${ }^{31,32}$ The physiological flat foot is eliminated by morphological changes during development. Theoretically, the plantar pressure thus tends to be distributed from the medial to the lateral side during growth. In the present study, the value of the leg-heel angle increased after the PHVA, indicating that the foot was close to inversion. 
Previous studies showed that patients with CAI are more laterally loaded than healthy subjects ${ }^{21}$ and that they exhibit reduced lateral support alignment. ${ }^{33,34}$ In the present study, leg-heel angle on weight-bearing during the PHVA phase showed a similar eversion angle to that of adults in the post-PHVA phase. These results suggest that the post-PHVA group exhibited a foot alignment similar to that of adults. Moreover, the ALM group was suspected to have decreased bony and ligamentous stability. Therefore, the post-PHVA group exhibited lateral loading during the heel raise as was shown in previous studies.

With respect to the decrease in the weight-bearing ankle dorsiflexion angle in the ALM group after the PHVA phase, several previous studies on LAS in adults reported a reduction in weight-bearing ankle dorsiflexion and ankle dorsiflexion angles. ${ }^{17,35} \mathrm{~A}$ decrease in soft tissue flexibility occurs in pediatric and adolescent children due to the rapid bone growth during the PHVA phase. ${ }^{22}$ Moreover, the ossification of the talus, medial malleolus, and LM occurs simultaneously with the development of arch function, ${ }^{36}$ and the talocrural joint axis is similar to that in adults. The findings of this study also indicate that ankle dorsiflexion and weight-bearing ankle dorsiflexion angles are reduced in each PHVA group. Additionally, patients with CAI have been reported to have an increased anteromedial contact area of the talus upon ankle dorsiflexion-internal rotation during loading and an increased talocrural joint inversion, ${ }^{37}$ which may be related to a decreased dorsiflexion during loading. Therefore, the decrease in the weight-bearing ankle dorsiflexion angle occurred in the ALM group members with mid- and postPHVA, which is in support of the findings from previous studies.

The subjects included in the current study were young footballers aged 6-15 years of age, whereas those in previous studies were individuals above the high school age. Hence, physical characteristics at different growth stages should be considered. In this study, we investigated factors associated with ALM in players with and without LAS, including differences in physical characteristics based on the PHVA. As only soccer players were included in this study, it is necessary to examine whether similar results can be obtained in basketball and volleyball players, who also have a high LAS incidence. ${ }^{1,2}$ As for the measurement method, we did not quantify ligament laxity because we only evaluated the presence or absence of ALM using ultrasonography. The ICC for the inter-rater reliability of ATFL quantification using ultrasonography was reported to be 0.811 for those with more than 10 years of experience and skill but $0.390-0.524$ for the other medical staff. ${ }^{38}$ Furthermore, the sensitivity, specificity, intra-rater reliability, and inter-rater reliability for ATFL injury diagnosis were $98.5-100 \%, 95 \%, 0.858-0.907$, and 0.878 , respectively. ${ }^{39}$ While the intra-rater reliability of ultrasonography was considered to be good, the inter-rater reliability is likely to vary depending on years of experience and skill of the ultrasound examiner. In the present study, one examiner performed the ultrasonographic measurements; hence, they were considered to be reliable.

This study was subject to several limitations. First, the number of subjects included was limited; thus, it is necessary to consider whether similar results can be obtained in different subjects. Second, this study employed a crosssectional design; therefore, the exact time of LAS onset and the residual duration of ALM were unknown. Third, ligament laxity and bone strength were not measured; it is unclear whether these results indicate structural instability associated with ALM. Hence, quantitative laxity and bone strength should be measured in future studies.

\section{Conclusions}

The prevalence of ALM detected amongst the pediatric and adolescent soccer players was $17.6 \%$. Decreased ankle mobility and increased leg-heel angle and one-leg hop test were observed after mid-PHVA when compared with pre-PHVA. Moreover, the ALM group exhibited lateral loading during the heel raising among those in the post-PHVA phase and a decreased weight-bearing ankle dorsiflexion angle in the mid- and post-PHVA phase. This study was novel in that, to our knowledge, it was the first to investigate the prevalence of ALM in pediatric and adolescent soccer players, including healthy individuals. It has been suggested that pediatric and adolescent soccer players are more likely to develop severe LAS because they are of a mature age and they have fragile osteochondral structures. The findings indicate the importance of recognizing LAS in pediatric and adolescent patients, as well as early treatment for the secondary prevention of LAS. The use of ultrasonography was shown to be effective for this purpose. More prospective studies investigating the incidence of LAS and its risk factors in pediatric and adolescent players are required in the future. 


\section{Acknowledgments}

The authors thank the coach of the soccer club team for allowing them to participate in this research and Hirose laboratory staff for supporting with the measurements.

\section{Author Contributions}

All authors made substantial contributions to conception and design, acquisition of data, or analysis and interpretation of data; took part in drafting the article or revising it critically for important intellectual content; agreed to submit to the current journal; gave final approval of the version to be published; and agree to be accountable for all aspects of the work.

\section{Disclosure}

The authors report no conflicts of interest in this work.

\section{References}

1. Swenson DM, Collins CL, Fields SK, Comstock RD. Epidemiology of U.S. high school sports-related ligamentous ankle injuries, 2005/ 06-2010/11. Clin J Sport Med. 2013;23(3):190-196. doi:10.1097/ JSM.0b013e31827d $21 \mathrm{fe}$

2. Hootman JM, Dick R, Agel J. Epidemiology of collegiate injuries for 15 sports: summary and recommendations for injury prevention initiatives. J Athl Train. 2007;42(2):311-319.

3. Bischof JE, Spritzer CE, Caputo AM, et al. In vivo cartilage contact strains in patients with lateral ankle instability. J Biomech. 2010;43 (13):2561-2566. doi:10.1016/j.jbiomech.2010.05.013

4. Takao M, Uchio Y, Naito K, Fukazawa I, Ochi M. Arthroscopic assessment for intra-articular disorders in residual ankle disability after sprain. Am J Sports Med. 2005;33(5):686-692. doi:10.1177/ 0363546504270566

5. Mandarakas M, Pourkazemi F, Sman A, Burns J, Hiller CE. Systematic review of chronic ankle instability in children. $J$ Foot Ankle Res. 2014;7(1):21. doi:10.1186/1757-1146-7-21

6. Hiller CE, Refshauge KM, Herbert RD, Kilbreath SL. Intrinsic predictors of lateral ankle sprain in adolescent dancers: a prospective cohort study. Clin J Sport Med. 2008;18(1):44-48. doi:10.1097/ JSM.0b013e31815f2b35

7. Yamaguchi S, Akagi R, Kimura S, et al. Avulsion fracture of the distal fibula is associated with recurrent sprain after ankle sprain in children. Knee Surg Sports Traumatol Arthrosc. 2019;27(9):27 74-2780. doi:10.1007/s00167-018-5055-7

8. Wisthoff B, Matheny S, Struminger A, et al. Ankle strength deficits in a cohort of college athletes with chronic ankle instability. J Sport Rehabil. 2019;28(7):752-757. doi:10.1123/ jsr.2018-0092

9. Boutis K, Plint A, Stimec J, et al. Radiograph-negative lateral ankle injuries in children: occult growth plate fracture or sprain? JAMA Pediatr. 2016;170(1):e154114. doi:10.1001/jamapediatrics. 2015.4114

10. Szczepaniak J, Ciszkowska-Lyson B, Smigielski R, Zdanowicz U. Value of ultrasonography in assessment of recent injury of anterior talofibular ligament in children. J Ultrason. 2015;15(62):259-266. doi:10.15557/JoU.2015.0022

11. Kwak YH, Lim JY, Oh MK, Kim WJ, Park KB. Radiographic diagnosis of occult distal fibular avulsion fracture in children with acute lateral ankle sprain. J Pediatr Orthop. 2015;35(4):352-357. doi:10.1097/BPO.0000000000000271
12. El Ashry SR, El Gamal TA, Platt SR. Atypical chronic ankle instability in a pediatric population secondary to distal fibula avulsion fracture nonunion. $J$ Foot Ankle Surg. 2017;56(1):148-152. doi:10.1053/j.jfas.2016.04.018

13. Hiller CE, Kilbreath SL, Refshauge KM. Chronic ankle instability: evolution of the model. $J$ Athl Train. 2011;46(2):133-141. doi:10. 4085/1062-6050-46.2.133

14. Fousekis K, Tsepis E, Vagenas G. Intrinsic risk factors of noncontact ankle sprains in soccer: a prospective study on 100 professional players. Am J Sports Med. 2012;40(8):1842-1850. doi:10.1177/ 0363546512449602

15. Kobayashi T, Tanaka M, Shida M. Intrinsic risk factors of lateral ankle sprain: a systematic review and meta-analysis. Sports Health. 2016;8(2):190-193. doi:10.1177/1941738115623775

16. de Noronha M, Refshauge KM, Herbert RD, Kilbreath SL, Hertel J. Do voluntary strength, proprioception, range of motion, or postural sway predict occurrence of lateral ankle sprain? Br J Sports Med. 2006;40(10):824-828. doi:10.1136/bjsm.2006.029645

17. Kobayashi T, Yoshida M, Yoshida M, Gamada K. Intrinsic predictive factors of noncontact lateral ankle sprain in collegiate athletes: a case-control study. Orthop J Sports Med. 2013;1(7):23259 67113518163. doi:10.1177/2325967113518163

18. Arnold BL, De La Motte S, Linens S, Ross SE. Ankle instability is associated with balance impairments: a meta-analysis. Med Sci Sports Exerc. 2009;41(5):1048-1062. doi:10.1249/MSS.0b013e318192d044

19. Docherty CL, Arnold BL, Gansneder BM, Hurwitz S, Gieck J. Functional-performance deficits in volunteers with functional ankle instability. $J$ Athl Train. 2005;40(1):30-34.

20. Ko J, Rosen AB, Brown CN. Functional performance tests identify lateral ankle sprain risk: a prospective pilot study in adolescent soccer players. Scand J Med Sci Sports. 2018;28(12):2611-2616. doi:10. 1111/sms.13279

21. Mineta S, Inami T, Mariano R, Hirose N. High lateral plantar pressure is related to an increased tibialis anterior/fibularis longus activity ratio in patients with recurrent lateral ankle sprain. Open Access J Sports Med. 2017;8:123-131. doi:10.2147/OAJSM.S131596

22. Philippaerts RM, Vaeyens R, Janssens M, et al. The relationship between peak height velocity and physical performance in youth soccer players. J Sports Sci. 2006;24(3):221-230. doi:10.1080/ 02640410500189371

23. Read PJ, Oliver JL, De Ste Croix MBA, Myer GD, Lloyd RS. Hopping and landing performance in male youth soccer players: effects of age and maturation. Int $J$ Sports Med. 2017;38 (12):902-908. doi:10.1055/s-0043-114009

24. Ali MA, Ohtsuki F. Prediction of adult stature for Japanese population: a stepwise regression approach. Am J Hum Biol. 2001;13 (3):316-322. doi:10.1002/ajhb.1055

25. Maeda M, Maeda N, Takaoka T, Tanaka Y. Sonographic findings of chondral avulsion fractures of the lateral ankle ligaments in children. J Ultrasound Med. 2017;36(2):421-432. doi:10.7863/ultra.15.09008

26. Takakura Y, Yamaguchi S, Akagi R, et al. Diagnosis of avulsion fractures of the distal fibula after lateral ankle sprain in children: a diagnostic accuracy study comparing ultrasonography with radiography. BMC Musculoskelet Disord. 2020;21(1):276. doi:10. 1186/s12891-020-03287-1

27. Matsuda S, Fukubayashi T, Hirose N. Characteristics of the foot static alignment and the plantar pressure associated with fifth metatarsal stress fracture history in male soccer players: a case-control study. Sports Med Open. 2017;3(1):27. doi:10.1186/s40798-017-0095-y

28. Hertel J, Miller JS, Denegar CR. Intratester and intertester reliability during the star excursion balance tests. J Sport Rehabil. 2000;9 (2):104-116. doi:10.1123/jsr.9.2.104

29. Meylan C, McMaster T, Cronin J, et al. Single-leg lateral, horizontal, and vertical jump assessment: reliability, interrelationships, and ability to predict sprint and change-of-direction performance. J Strength Cond Res. 2009;23(4):1140-1147. doi:10.1519/JSC.0b013e318190f9c2 
30. Reiner MM, Sharpe JJ. The role of the accessory malleolar ossicles and malleolar avulsion fractures in lateral ankle ligament reconstruction. Foot Ankle Spec. 2018;11(4):308-314. doi:10.1177/ 1938640017729498

31. Tong JW, Kong PW. Medial longitudinal arch development of children aged 7 to 9 years: longitudinal investigation. Phys Ther. 2016;96 (8):1216-1224. doi:10.2522/ptj.20150192

32. Uden H, Scharfbillig R, Causby R. The typically developing paediatric foot: how flat should it be? A systematic review. J Foot Ankle Res. 2017;10(1):37. doi:10.1186/s13047-017-0218-1

33. Kobayashi T, Saka M, Suzuki E, et al. In vivo kinematics of the talocrural and subtalar joints during weightbearing ankle rotation in chronic ankle instability. Foot Ankle Spec. 2014;7(1):13-19. doi:10.1177/1938640013514269

34. Kobayashi T, Suzuki E, Yamazaki N, et al. Fibular malalignment in individuals with chronic ankle instability. J Orthop Sports Phys Ther. 2014;44(11):872-878. doi:10.2519/jospt.2014.5217

35. Willems TM, Witvrouw E, Delbaere K, et al. Intrinsic risk factors for inversion ankle sprains in females-a prospective study. Scand J Med Sci Sports. 2005;15(5):336-345. doi:10.1111/j.1600-0838.2004.00428.x
36. Ogden JA, McCarthy SM. Radiology of postnatal skeletal development. VIII. Distal tibia and fibula. Skeletal Radiol. 1983;10 (4):209-220. doi:10.1007/BF00357893

37. Kobayashi T, Suzuki E, Yamazaki N, et al. In vivo talocrural joint contact mechanics with functional ankle instability. Foot Ankle Spec. 2015;8(6):445-453. doi:10.1177/1938640015585967

38. Kristen KH, Seilern Und Aspang J, Wiedemann J, Hartenbach F, Platzgummer H. Reliability of ultrasonography measurement of the anterior talofibular ligament (ATFL) length in healthy subjects (in vivo), based on examiner experience and patient positioning. J Exp Orthop. 2019;6(1):30. doi:10.1186/s40634-019-0199-z

39. Lee SH, Yun SJ. The feasibility of point-of-care ankle ultrasound examination in patients with recurrent ankle sprain and chronic ankle instability: comparison with magnetic resonance imaging. Injury. 2017;48(10):2323-2328. doi:10.1016/j.injury.2017.07.015

\section{Publish your work in this journal}

Open Access Journal of Sports Medicine is an international, peerreviewed, open access journal publishing original research, reports, reviews and commentaries on all areas of sports medicine. The manuscript management system is completely online and includes a very quick and fair peer-review system. Visit http://www.dovepress. com/testimonials.php to read real quotes from published authors. 